\title{
Toxicity study of lead naphthenate
}

\author{
TH. VAN PETEGHEM ${ }^{1}$ and H. DE VOS ${ }^{2}$ \\ Department of Hygiene and Social Medicine, Akademisch Ziekenhuis, University of Gent ${ }^{2}$ \\ and Medical Service, N.V. SIDMAR, Belgium ${ }^{1}$
}

van Peteghem, Th., and de Vos, H. (1974). British Journal of Industrial Medicine, 31, 233-238. Toxicity study of lead naphthenate. Lead naphthenate is added to oils and greases in order to increase their resistance to high pressures. Experiments on animals and humans showed the possibility of a small amount of percutaneous absorption.

An investigation was performed on technicians regularly dealing with these lubricants in order to explore to what extent they had absorbed the lead naphthenate. The degree of absorption was evaluated by measuring the lead content of the blood and the $\delta$-aminolevulinic acid concentration in the urine.

Individual results did not permit clearcut conclusions whether an increase in lead absorption had occurred or not. Therefore the group of technicians was compared with a group without any occupational contact with lead-containing lubricants but otherwise comparable in occupational and general exposure to lead.

To test the significance of the difference between the means of the samples a one-sided $t$ test not assuming equal standard deviations for both populations was used. For any of two compared populations the $t$ test was repeated after rejection of the larger values which were 2.5 standard deviations from the mean value in the exposed population. It appeared that the lead concentration in the blood and the $\delta$-aminolevulinic acid concentration in the urine of people exposed to lead naphthenate-containing lubricants were significantly higher than those concentrations observed in non-exposed persons.

From a routine investigation of the chemical composition of oils and greases used in the N.V. SIDMAR steel plant, it appeared that several of these lubricants were loaded with lead compounds of naphthenic acid. About one thousand factory employees, mainly from the maintenance department, are in more or less daily contact with these substances.

Knowledge of the toxicity of lead naphthenate in man is quite inadequate. Indeed, since the initial study by Rockhold (1955), only five papers have been published on this subject. Moreover, the application of lead naphthenate as an additive to industrial lubricants was unknown both to university laboratories and to the national labour inspectorate.

Lead naphthenate is a lead salt of naphthenic acid. Commercial naphthenic acid is a mixture of very small quantities of long-chained monobasic carboxylic acids and of large quantities of pentacyclic carboxylic acids.

Commercial lead naphthenate is usually available dissolved in white spirit, the solution containing about $24 \%$ lead. After addition to greases and oils, these compounds have a lead content of 2 to $7 \%$, depending on the properties required. The oils are used in gear boxes, and the greases in ball bearings. During operation, the increase in mechanical pressure gives rise to friction heat. This physical process causes the lead to dissociate from the naphthenate, and iron naphthenate, metallic lead, and lead sulphide are formed. The latter three compounds can be detected in used and degenerated oils and greases. In this way the soft metallic lead performs a lubricating role. 


\section{Toxicity of lead naphthenate in animals}

Rockhold (1955) performed a comparative study in order to determine the toxicity for rats of two commercial naphthenic acids and of several metalsalts of naphthenic acid. The acute oral toxicity of lead naphthenate is rather weak $\left(\mathrm{LD}_{50} \mathrm{~g} / \mathrm{kg}=5 \cdot 1\right)$; the acute peritoneal toxicity is about 10 times larger $\left(L_{50} \mathrm{~g} / \mathrm{kg}=0.52\right)$. The subacute or chronic toxicity is also very weak.

Lead secretion in the urine and in the faeces increased and an accumulation of lead in the hair was observed in rats given daily for 20 days $0.25 \mathrm{ml}$ of a lead naphthenate solution with a lead concentration of $1 \%$. No deaths were caused, however, and at necropsy no organic alteration whatsoever appeared. The dermal toxicity was not investigated.

Hine, Cavalli, and Beltran (1969) performed a skinloading experiment on rats with lead-containing oils, in which the lead content of the arterial blood increased to about four times the initial value.

Desoille, Derobert, Le Breton, and Martin (1951) demonstrated in rats that lead-containing cutting oils which are absorbed either orally, by the respiratory tract, or through the skin, caused an increase of the basophilic granulation of the red blood cells and of the liver lead content. Pathological changes in the kidneys were also observed.

In a subsequent experiment on rats (Desoille, Michon, and Truffert, 1956), lead absorption through the skin could not be confirmed.

\section{Toxicity of lead naphthenate in man}

Lead naphthenate is very toxic by mouth as the stomach acid converts the lead into lead chloride, which is easily absorbed.

Lead absorption through the human skin was investigated in two experiments on human volunteers. Rasetti et al. (1961) performed a first skinloading experiment on three volunteers whose skin was loaded at a well-defined spot with $6 \mathrm{ml}$ oil containing $192 \mathrm{mg}$ lead. After 5, 10, 30, 60, 210, and 480 minutes the lead content of the venous blood was determined. After 10 minutes the lead content increased, and reached more than $300 \%$ of its initial value after 30 to 60 minutes. After 8 hours the lead concentration had dropped to its initial value.

Hine et al. (1969) performed another skinloading experiment on 10 volunteers. Gear oil containing $1.35 \%$ lead naphthenate was applied to the skin over 20 days, i.e., $60 \mathrm{ml}$ oil in total or $0.81 \mathrm{~g}$ lead. The symptoms of these subjects were not characteristic of lead poisoning in any way. The coproporphyrin content of the urine was normal.

In two papers lead poisoning has been described in employees having contact with lead-containing oils and greases. Pettinati, Rasetti, and Rubino (1959) mention four cases in employees in charge of the maintenance of lifting devices working on leadcontaining oil.

Two persons had gastroenterological complaints, and two others suffered from stiffness in the knee joints which disappeared after calcium versenate treatment. Three persons employed in this job for over five years had an increased concentration of lead and coproporphyrin in the urine. In addition, after submitting them to a Ca-EDTA provocation test, a marked increase in lead secretion in the urine was observed. No abnormal values in the biological tests were detected in a person who had been performing this maintenance job for only eight months.

A second report (Rasetti, Cappellaro, and Gaido, 1961) concerned 11 men performing maintenance work in a hot mill and hence in frequent contact with lead-containing oil. Two of them suffered from anaemia, and in three others there was increased lead in the urine. As the lead content of the environmental air was very low, the authors concluded that these findings were due to percutaneous absorption from contact with the lead-containing oils.

From the experiments on animals it may be argued that lead naphthenate can be absorbed as well orally or through the skin as through the respiratory tract.

The degree of lead absorption can be measured by the increased lead content of the blood, urine, and liver.

Skinloading experiments with lead naphthenate on humans confirm the results of experiments in animals. Indirect biological indications of lead toxicity are evident-increase of the coproporphyrin level of the urine, increase in the number of red blood cells with basophilic granulation, and anaemia. It appears that unlike tetramethyl lead the lead ion of the organic naphthenate lead is set free in the organism.

The lead component of lead naphthenate is thus responsible for its toxicity, as the naphthenic acid itself is hardly toxic (Rockhold, 1955).

\section{Investigations}

The technicians of the maintenance department and the assemblers of the cylinders of the cold rolling mill department were examined. These men clean and lubricate engines which are driven by electric motors so that occupational exposure to lead-containing petrol does not exist.

The lead content of the blood was determined according to Hessel (1968) by means of a Unicam atomic absorption spectrometer at a wavelength of $283.3 \mathrm{~nm}$. The analysis of the $\delta$-aminolevulinic acid was performed by the method of Davis and Andelman (1967).

The individual results of lead determination in the blood of nonexposed employees are given in Table 1, 
and the $\delta$-aminolevulinic acid concentration in their urine in Table 2.

\section{TABLE 1}

Lead Content of Blood of 10 Male Employees having No Occupational Contact With Lead

\begin{tabular}{c|c}
\hline & $\begin{array}{c}P b \\
\text { Rank subjects }\end{array}$ \\
\hline 1 & 12 \\
2 & 12 \\
3 & 24 \\
4 & 18 \\
5 & 12 \\
6 & 20 \\
7 & 25 \\
8 & 16 \\
9 & 10 \\
10 & 11 \\
\hline Mean value & 16 \\
Standard deviation & $5 \cdot 51$ \\
\hline
\end{tabular}

TABLE 2

$\delta$-Aminolevulinic Acid Concentration of Urine of 10 Men Not OCCUPATIONALly EXPOSED to LEAD

\begin{tabular}{c|c}
\hline Rank subjects & ALA (mg/l urine $)$ \\
\hline 1 & $2 \cdot 5$ \\
2 & $3 \cdot 5$ \\
3 & $3 \cdot 0$ \\
4 & $2 \cdot 5$ \\
5 & $0 \cdot 0$ \\
7 & $2 \cdot 0$ \\
8 & $1 \cdot 5$ \\
9 & $4 \cdot 5$ \\
10 & $3 \cdot 5$ \\
& $3 \cdot 0$ \\
\hline Mean value & $2 \cdot 60$ \\
Standard deviation & $1 \cdot 24$ \\
\hline
\end{tabular}

\section{Blood lead content of technicians}

A first investigation of the lead content of the blood of nine technicians working with lead-containing lubricants and chosen at random yielded the results summarized in Table 3. The six values marked with an asterisk are somewhat higher than the highest 'normal' value (the sum of the mean value and twice the standard deviation) for persons who are not occupationally exposed to lead-27.02 $\mu \mathrm{g}$ lead $/ 100 \mathrm{ml}$ blood. These results are, however, far below the maximum acceptable value of $70 \mu \mathrm{g}$ lead$/ 100 \mathrm{ml}$ blood. These individual results as such did not permit a statistical conclusion whether or not an increase in lead absorption had occurred in the personnel of the main-
TABLE 3

Blood Lead Content of 9 Technicians Working WITH LEAD-CONTAINING LUBRICANTS

\begin{tabular}{c|c}
\hline Rank subjects & $P b(\mu \mathrm{g} / 100 \mathrm{ml}$ blood $)$ \\
\hline 1 & 22 \\
2 & 22 \\
$3^{*}$ & 30 \\
$4^{*}$ & 30 \\
$5^{*}$ & 32 \\
$6^{*}$ & 29 \\
7 & 26 \\
$8^{*}$ & 34 \\
$9^{*}$ & 28 \\
\hline Mean value & $28 \cdot 11$ \\
Standard deviation & $3 \cdot 90$ \\
\hline
\end{tabular}

tenance department. Therefore the results of this experiment (Table 3) were compared with the results of lead determination in the blood of 10 members of the N.V. SIDMAR personnel who were not occupationally exposed to lead (Table 1).

A one-sided $t$ test, without assuming equal standard deviations in both populations, was thought the most suitable technique to test the significance of the difference between sample means. The calculated $t$ value is 6.061 , which means that the difference is significant at the $0.05 \%$ level.

In a second investigation, the lead content of the blood of 69 technicians, chosen at random, was determined. The results are given in Table 4 . The 31 values marked with an asterisk are higher than the normal highest value for individuals not occupationally exposed to lead. All of these values but one (no. 45) are situated below the maximum acceptable value. By means of a one-sided $t$ test, a comparison was made between the lead content of the blood of the 69 technicians (Table 4) and of the 10 employees having no professional contact with leadcontaining oil (Table 1).

The calculated $t$ value is 5.486 , which means that the difference between sample means is significant at the $0.05 \%$ level.

After rejection of the two larger values (nos. 45 and 49) exceeding 2.5 times the standard deviation in Table 4 a new $t$ test was performed. The resulting $t$ value is 4.972 , so the difference is still significant at the $0.05 \%$ level.

The lead content of the blood of 26 assemblers of the cold mill department, randomly selected, was determined. The results are given in Table 5. The 13 values marked with an asterisk are higher than the normal highest level for employees not occupationally exposed to lead. All of them, however, are situated below the maximum acceptable concentration.

A comparison was made between the lead content of the blood of the 26 assemblers of the cold mill department (Table 5) and of the 10 employees not occupationally exposed to lead (Table 1). The calculated $t$ value is $5 \cdot 259$, which means that the difference is significant at the $0.05 \%$ level.

After rejection of the extreme observation (no. 10) a 
TABLE 4

Blood Lead Content of 69 Technicians

\begin{tabular}{|c|c|c|c|c|c|}
\hline Rank subjects & $\mathrm{Pb}(\mu \mathrm{g} / 100 \mathrm{ml}$ blood $)$ & Rank subjects & $\mathrm{Pb}(\mu \mathrm{g} / 100 \mathrm{ml}$ blood $)$ & Rank subjects & $\mathrm{Pb}(\mu \mathrm{g} / 100 \mathrm{ml}$ blood $)$ \\
\hline $\begin{array}{c}1 \\
2 \\
3 \\
4 \\
5 \\
6^{*} \\
7^{*} \\
8^{*} \\
9^{*} \\
10^{*} \\
11^{*} \\
12 \\
13^{*} \\
14 \\
15^{*} \\
16^{*} \\
17^{*} \\
18 \\
19 \\
20 \\
21^{*} \\
22 \\
23^{*}\end{array}$ & $\begin{array}{l}27 \\
19 \\
16 \\
27 \\
16 \\
42 \\
32 \\
32 \\
29 \\
53 \\
32 \\
20 \\
32 \\
17 \\
37 \\
41 \\
30 \\
19 \\
26 \\
11 \\
39 \\
18 \\
34\end{array}$ & $\begin{array}{l}24 \\
25 \\
26 \\
27 \\
28^{*} \\
29 \\
30 \\
31 \\
32 \\
33 \\
34 \\
35 \\
36 \\
37 \\
38 \\
39^{*} \\
40 \\
41^{*} \\
42 \\
43^{*} \\
44^{*} \\
45^{*} \\
46^{*}\end{array}$ & $\begin{array}{l}23 \\
27 \\
20 \\
23 \\
31 \\
23 \\
18 \\
25 \\
23 \\
20 \\
22 \\
14 \\
18 \\
20 \\
24 \\
40 \\
22 \\
38 \\
18 \\
32 \\
40 \\
74 \\
46\end{array}$ & $\begin{array}{l}47 \\
48^{*} \\
49^{*} \\
50^{*} \\
51^{*} \\
52^{*} \\
53 \\
54^{*} \\
55 \\
56 \\
57 \\
58^{*} \\
59 \\
60^{*} \\
61^{*} \\
62^{*} \\
63 \\
64^{*} \\
65 \\
66 \\
67 \\
68^{*} \\
69\end{array}$ & $\begin{array}{l}26 \\
42 \\
59 \\
42 \\
30 \\
38 \\
26 \\
38 \\
26 \\
22 \\
22 \\
32 \\
16 \\
37 \\
32 \\
42 \\
22 \\
33 \\
25 \\
18 \\
25 \\
30 \\
11\end{array}$ \\
\hline
\end{tabular}

Mean value $28 \cdot 75$

Standard deviation $11 \cdot 15$

new $t$ test was performed. The calculated $t$ value is 6.980, so the difference is still significant at the $0.05 \%$ level.

Urine $\delta$-aminolevulinic acid concentration of technicians in maintenance department

An experiment was set up in order to examine the $\delta$ aminolevulinic acid in the urine of 102 technicians of the maintenance department chosen at random. The results

\section{TABLE 5}

Blood Lead Content of 26 Assemblers of the Cold Mill Department

\begin{tabular}{c|c|c|c}
\hline $\begin{array}{c}\text { Rank } \\
\text { subjects }\end{array}$ & $\begin{array}{c}P b(\mu \mathrm{g} / 100 \mathrm{ml} \\
\text { blood })\end{array}$ & $\begin{array}{c}\text { Rank } \\
\text { subjects }\end{array}$ & $\begin{array}{c}P b(\mu \mathrm{g} / 100 \mathrm{ml} \\
\text { blood })\end{array}$ \\
\hline 1 & 21 & 14 & 26 \\
$2^{*}$ & 30 & 15 & 24 \\
$3^{*}$ & 39 & $16^{*}$ & 30 \\
$4^{*}$ & 30 & $17^{*}$ & 28 \\
5 & 20 & $18^{*}$ & 28 \\
$6^{*}$ & 30 & $19^{*}$ & 29 \\
$7^{*}$ & 28 & 20 & 11 \\
$8^{*}$ & 28 & 21 & 19 \\
9 & 24 & 22 & 27 \\
$10^{*}$ & 46 & 23 & 21 \\
$11^{*}$ & 32 & 24 & 27 \\
12 & 22 & $25^{*}$ & 30 \\
13 & 22 & 26 & 26 \\
\hline Mean value & 26.84 & & \\
Standard deviation 6.48 & \\
\multicolumn{2}{|l}{} \\
\hline
\end{tabular}

are given in Table 6. The $13 \delta$-aminolevulinic acid concentrations exceeding the sum of the mean value plus twice the standard deviation and marked with an asterisk are higher than the highest normal value but are situated far below the maximum acceptable concentration.

By means of a one-sided $t$ test, a comparison was made between the $\delta$-aminolevulinic acid content of the urine of the 102 technicians (Table 6) and of urine specimens of 10 men having no occupational contact with lead (Table 2). The calculated $t$ value is $2 \cdot 222$, which means that the difference between sample-means is significant at the $5 \%$ level but not at the $2 \cdot 5 \%$ level.

After rejection of the extreme observations (nos. 59, 70 , and 80 ) a new $t$ test was performed. The new calculated $t$ value is 1.885 , so the difference is still significant at the $5 \%$ level but not at the $2 \cdot 5 \%$ level.

\section{Conclusions}

The lead content of the blood and the $\delta$-aminolevulinic acid concentration of the urine are higher in populations of employees working with leadcontaining oils than in populations having no occupational contact with these products. The probability that this is wrong is less than $0.05 \%$ in respect of the lead content of the blood and less than $5 \%$ in respect of the $\delta$-aminolevulinic acid content of the urine.

One hundred and four persons chosen at random are involved in the three investigations on employees who have occupational contact with lead-containing oils and whose blood lead content has been deter- 
TABLE 6

$\delta$-Aminolevulinic Acid Concentration of Urine of 102 Technicians

\begin{tabular}{|c|c|c|c|c|c|}
\hline Rank subjects & $A L A(m g / l$ urine $)$ & Rank subjects & $A L A$ (mg/l urine) & Rank subjects & $A L A$ (mg/l urine) \\
\hline 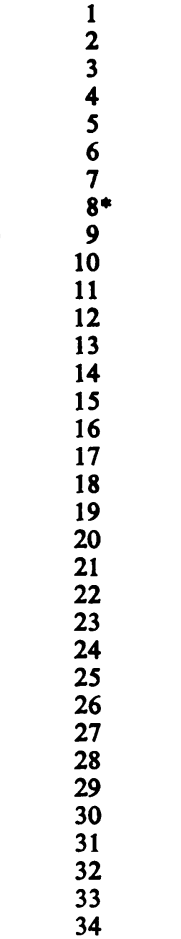 & $\begin{array}{l}5.0 \\
3.5 \\
2.5 \\
2.5 \\
5.0 \\
2.5 \\
3.5 \\
6.5 \\
3.0 \\
2.5 \\
3.5 \\
3.5 \\
2.0 \\
2.0 \\
2.0 \\
2.0 \\
2.0 \\
3.5 \\
2.0 \\
1.5 \\
4.5 \\
255 \\
3.0 \\
5.0 \\
1.0 \\
1.5 \\
2.0 \\
3.0 \\
2.0 \\
1.5 \\
3.0 \\
1.5 \\
2.0 \\
3.0\end{array}$ & 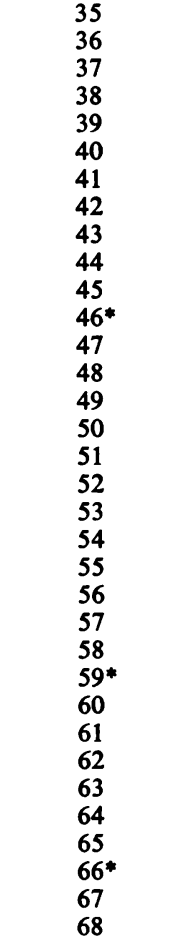 & $\begin{array}{l}2.0 \\
3.0 \\
1.5 \\
2.0 \\
3.0 \\
1.0 \\
3.0 \\
1.0 \\
1.5 \\
4.0 \\
4.5 \\
6.0 \\
4.0 \\
3.5 \\
4.5 \\
1.5 \\
2.5 \\
5.0 \\
4.0 \\
1.5 \\
4.0 \\
3.0 \\
3.5 \\
2.5 \\
8.0 \\
2.0 \\
4.5 \\
3.0 \\
4.0 \\
3.0 \\
5.0 \\
5.5 \\
5.0 \\
3.5\end{array}$ & $\begin{array}{l}69 \\
70^{*} \\
71 \\
72^{*} \\
73^{*} \\
74 \\
75 \\
76 \\
77 \\
78 \\
79 \\
80^{*} \\
81 \\
82 \\
83 \\
84 \\
85^{*} \\
86 \\
87 \\
88^{*} \\
89^{*} \\
90 \\
91 \\
92 \\
93 \\
94 \\
95^{*} \\
96 \\
97 \\
98 \\
99 \\
100 \\
101 \\
102\end{array}$ & 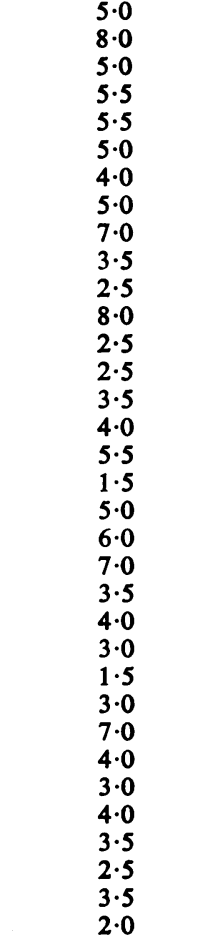 \\
\hline $\begin{array}{l}\text { an value } \\
\text { ndard deviat }\end{array}$ & $\begin{array}{l}3 \cdot 50 \\
1.62\end{array}$ & & & & \\
\hline
\end{tabular}

mined (Tables 3, 4, and 5). Of these 104 employees, only 12 (i.e., $8.5 \%$ ) show a blood lead content higher than or equal to $40 \mu \mathrm{g} / 100 \mathrm{ml}$.

On the other hand, it is remarkable that, of the 102 employees having occupational contact with lead-containing oils and whose urine $\delta$-aminolevulinic acid content has been determined (Table 6), 13 persons (i.e., $7 \cdot 8 \%$ ) show a $\delta$-aminolevulinic acid concentration of the urine exceeding the 'normal' highest value of $5.4 \mathrm{mg} /$ litre urine.

These two percentages are practically equal and confirm the increase of $\delta$-aminolevulinic acid in the urine when the lead content of the blood reaches the threshold of $40 \mu \mathrm{g} / 100 \mathrm{ml}$ (Selander and Cramér, 1970).

From the evidence presented it appears that $8 \%$ of the employees having occupational contact with lead-containing oils show a blood lead content of over $40 \mu \mathrm{g} / 100 \mathrm{ml}$ and have also an increased $\delta$ aminolevulinic acid secretion. It must be pointed out, however, that these increased values are all situated below the maximum acceptable concentration.

From these facts it may be deduced that the periodic determination of $\delta$-aminolevulinic acid excretion in the urine and of the blood lead content is of no use for the early detection and evaluation of the individual degree of exposure to lead in persons working with lead-containing oils.

From this study we can conclude that under working conditions, lead naphthenate-containing oils and greases provoke biological reactions in the haem cycle, but these reactions are acceptable in terms of lead toxicity.

We wish to thank the department Info-Research Sidmar for statistical advice.

\section{References}

Davis, J. R. and Andelman, S. L. (1967). Urinary deltaaminolevulinic acid (ALA) levels in lead poisoning $\mathrm{I}$. 
A modified method for the rapid determination of urinary delta-aminolevulinic acid using disposable ion-exchange chromatography columns. Archives of Environmental Health, 15, 53-59.

Desoille, H., Derobert, L., Le Breton, R., and Martin, R. (1951). Du danger de saturnisme au cours de l'utilisation des huiles de coupe plombifères. Archives des Maladies Professionnelles, 12, 416-423. - Michon, R., and Truffert, L. (1956). À propos de l'emploi d'une huile de coupe plombifère et soufrée. Archives des Maladies Professionnelles, 17, 582-585.

Fieser, L. F. and Fieser, M. (1956). Organic Chemistry, 3rd edition, p. 97. Reinhold Publishing Corporation, New York.

Forbes, W. G. (1961). Lubrication of Industrial and Marine Machinery, 2nd edition, p. 60. John Wiley, New York.

Hessel, D. W. (1968). A simple and rapid quantitative determination of lead in blood. Atomic Absorption Newsletter, 7, 55-56.

Hine, C. H., Cavalli, R. D., and Beltran, S. M. (1969). Percutaneous absorption of lead from industrial lubricants. Journal of Occupational Medicine, 11, 568-575.

Pettinati, L., Rasetti, L., and Rubino, G. (1959). Intossicazione da naftenato di piombo contenuto negli olii lubrificanti per sistemi idropneumatici. Rassegna de Medicina Industriale e di Igiene del Lavoro, 28, 379-385.

Rasetti, L., Cappellaro, F., and Gaido, P. (1961). Contributo allo studio del saturnismo da olii lubrificanti addittivati. Rassegna di Medicina Industriale e di Igiene de Lavoro, 30, 71-75.

Rockhold, W. T. (1955). Toxicity of naphthenic acids and their metal salts. Archives of Industrial Health, $12,477-482$.

Selander, S., and Cramér, K. (1970). Interrelationships between lead in blood, lead in urine, and ALA in urine during lead work. British Journal of Industrial Medicine, 27, 28-39.

Received for publication 24 July 1973

Accepted for publication 27 November 1973 